\title{
Participación y calidad democrática. Evaluando las nuevas formas de democracia participativa Marc Parés (coordinador)
}

\author{
Editorial Ariel, Barcelona, 2009, 471 págs. \\ Juan Alberto Castañeda Alcaino \\ Pontificia Universidad Católica de Chile, Santiago, Chile. Email: jcastana@uc.cl
}

Desde inicios de la reciente década, diversos especialistas comenzaron un intenso debate sobre la pertinencia y necesidad de introducir en los sistemas democráticos occidentales, nuevos mecanismos de consulta o participación ciudadana. La publicación coordinada por Marc Parés, Doctor en Ciencias Ambientales y Cientista Político por la Universidad Autónoma de Barcelona, resulta un interesante y reflexivo análisis sobre diversos ejemplos de participación ciudadana. La pregunta central de la obra es ¿de qué calidad democrática se habla en estas nuevas formas de participación?

El libro, recoge los aportes de diversos especialistas en participación ciudadana. Desde la Ciencia Política, pasando por la Sociología y la Psicología, el texto introduce al lector tanto en el debate contemporáneo sobre las nuevas formas de participación (aspectos normativos), hasta llegar a casos concretos donde la ciudadanía se ha mostrado empoderada para enfrentar temáticas como políticas presupuestarias municipales, inmigratorias, sistemas de fiscalización o de rendición de cuentas.

La investigación publicada en septiembre del año 2009 por la Editorial Ariel se divide en 17 capítulos -incluyendo las conclusiones-, constituida en cuatro partes. En la primera -Participación ciudadana, calidad democrática y evaluación- se abordan desde aspectos normativos que sustentan los principios y mecanismos de participación hasta experiencias comparadas de participación en especial en el ámbito municipal. Destacan aquí a mi entender tres capítulos. El número 3 titulado "las distintas concepciones de democracia en el mundo local y sus efectos en la participación ciudadana: la definición de escenarios posibles”. Un capítulo fundamental ya que orienta las concepciones teóricas y epistemológicas que orientan los diseños de Políticas Públicas en el ámbito local. El 5 titulado "factores que explican la participación: comparando recursos, relaciones y normas en cinco países europeos”, de los autores Vivien Lowndes y Lawrence Pratchett, analizan las experiencias de participación en 23 municipios de cinco países de Europa (Finlandia, Holanda, Noruega, Eslovaquia y España), aplicando para el análisis comparativo la metodología CLEAR (en su acrónimo en inglés), 
que proporciona una herramienta de diagnóstico para las autoridades locales y diversos organismos públicos. Utilizando esta herramienta, se sostiene que la participación es efectiva cuando los ciudadanos: i) pueden hacer, es decir, los ciudadanos cuentan con los recursos y el conocimiento para participar (C, cant do); ii) tienen sentido de comunidad lo que favorece culturalmente la participación (L, like to); iii) están proveídos de oportunidades para participar ( $\mathrm{E}$, enabled to); iv) están movilizados por grupos públicos o voluntarios (A, asked to); y v) ven evidencias de que sus puntos de vista han sido considerados ( $\mathrm{R}$, responsed to). El tercer capítulo, central a mi juicio, es el número 7 titulado “¿por qué y cómo evaluar la participación?”. En este se abordan elementos centrales de la investigación como son ¿qué evaluar en la participación?, la importancia de los procesos evaluativos para esta dimensión de la democracia, diseños de evaluación, el establecimiento de criterios de evaluación y el rol de los evaluadores.

En la segunda parte se abordan los roles, estructura y funcionamiento de los espacios estables de participación ciudadana, además de analizar casos como los de Barcelona y Aragón. En este punto se advierte a mí entender una debilidad de la investigación: la capacidad de establecer generalidades tanto del caso español como el europeo con escaso número de objetos de estudio. Pese a esto, la obra aborda en el capítulo 10 un tema de alta importancia para los países que han enfrentado -y lo siguen haciendoprocesos migratorios. Punto no menor si se consideran las emergentes problemáticas de sociedades globalizadas que atraviesan intensos flujos migratorios.

En la tercera parte, constituida por los capítulos 11 al 14 se abordan temáticas de enorme importancia para la evaluación de los procesos de implicación ciudadana. Entre estos se logran identificar: i) criterios de calidad democrática para evaluar procesos participativos; ii) evaluación de los procesos de participación en el caso de los municipios catalanes, recogiendo experiencias recientes; iii) evaluación de los procesos participativos en las políticas públicas consideradas como estratégicas; iv) el caso de los presupuestos participativos de Porto Alegre. En este último apartado y gracias a un análisis pormenorizado se abordan dimensiones como la participación por género, edad, nivel de formación, etnia y renta familiar entre otras. Aquí el análisis destaca y se infiere lo fundamental del estudio al resaltar elementos de identidad cultural y contextos situacionales.

La cuarta y última parte presenta 3 capítulos y la conclusión de la investigación. En esta parte se analizan, según entiendo, elementos claves en el diseño de Políticas Públicas que buscan analizar y ejecutar proyectos de implicación ciudadana. Resaltan aquí los estudios sobre la calidad de la democracia y formas de evaluar la participación; el marco de análisis de Políticas Públicas en dimensiones como el aprovisionamiento del agua en Cataluña, las políticas de regeneración urbana con participación de los ciudadanos y, la diversidad de propuestas y las calidades de éstas gracias a la participación de los ciudadanos españoles. En torno a las políticas de regeneración en las ciudades, la obra aborda tres preguntas pertinentes 
para un análisis crítico de esta dimensión. La primera, ¿qué peso específico tiene la participación ciudadana en distintas redes de gobernanza para la regeneración urbana?; la segunda, ¿qué consecuencias tiene la participación ciudadana?; la tercera, qué tipo de factores explican la variabilidad en las pautas y en la calidad de la participación ciudadana? (Parés, 2009, p.423). Se concluye aquí que la legitimidad democrática sería mayor cuando la ciudadanía tenga un mayor peso en relación a los otros actores (gubernamentales y empresas privadas).

La obra finalmente recoge tres tensiones presentes en los enfoques sobre análisis de participación ciudadana. El primero, la tensión en las autoridades sobre las concepciones que orientan la participación (Estados-liberal representativos versus democracia radical). El segundo, las tensiones entre los enfoques normativos y las lógicas del contexto. Y el tercero, la multiplicidad de formas de evaluación sobre la participación y sus aportes a los modelos democráticos. 